\title{
Ligand Size and Chain Length Study of Silver Carboxylates in Focused Electron Beam Induced Deposition
}

\author{
Jakub Jurczyk ${ }^{1,2}$, Katarzyna Madajska ${ }^{3}$, Luisa Berger ${ }^{1}$, Leo Brockhuis ${ }^{1,2}$, Thomas E. J. Edwards ${ }^{1}$, \\ Katja Höflich ${ }^{4,5}$, Czesław Kapusta ${ }^{2}$, Iwona Szymanska ${ }^{3}$, Ivo Utke ${ }^{1^{*}}$ \\ ${ }^{1}$ Empa - Swiss Federal Laboratories for Materials Science and Technology, Laboratory for Mechanics of \\ Materials and Nanostructures, Feuerwerkerstrasse 39, CH - 3602 Thun, Switzerland \\ ${ }^{2}$ AGH University of Science and Technology Krakow, Faculty of Physics and Applied Computer Science, Al. \\ Mickiewicza 30, 30-059 Kraków, Poland \\ ${ }^{3}$ Faculty of Chemistry, Nicolaus Copernicus University in Toruń, Gagarina 7, 87-100 Toruń, Poland \\ ${ }^{4}$ Helmholtz-Zentrum Berlin für Materialien und Energie, Nanoscale Structures and Microscopic Analysis, \\ Hahn-Meitner-Platz 1, D - 14109 Berlin, Germany \\ ${ }^{5}$ Ferdinand-Braun Institut, Leibniz-Institut für Höchstfrequenztechnik, Gustav-Kirchhoff-Str. 4, 12489 Berlin, \\ Germany \\ * Correspondence: ivo.utke@empa.ch;
}

\begin{abstract}
Focused electron beam induced deposition is a versatile tool for the direct fabrication of complex-shaped nanostructures with unprecedented shape fidelity and resolution. While the technique is well-established for various materials, the direct electron beam writing of silver is still in its infancy. Here, five different silver carboxylates, three fluorinated: $\left[\mathrm{Ag}_{2}\left(\mu-\mathrm{O}_{2} \mathrm{CCF}_{3}\right)_{2}\right],\left[\mathrm{Ag}_{2}(\mu-\right.$ $\left.\left.\mathrm{O}_{2} \mathrm{CC}_{2} \mathrm{~F}_{5}\right)_{2}\right],\left[\mathrm{Ag}_{2}\left(\mu-\mathrm{O}_{2} \mathrm{CC}_{3} \mathrm{~F}_{7}\right)_{2}\right]$ and two containing hydrogen: $\left[\mathrm{Ag}_{2}\left(\mu-\mathrm{O}_{2} \mathrm{CCMe}_{2} \mathrm{Et}_{2}\right]\right.$ and $\left[\mathrm{Ag}_{2}(\mu-\right.$ $\left.\left.\mathrm{O}_{2} \mathrm{C}^{\mathrm{t}} \mathrm{Bu}\right)_{2}\right]$ were examined and compared as potential precursors for focused electron beam induced deposition. All of the compounds show high sensitivity to electron dissociation and efficient dissociation of Ag-O bonds. The as-deposited materials showed high silver content from 42 at. $\%$ to above 70 at.\% and silver nano-crystal formation with impurities of carbon and fluorine incorporated between metal grains. A correlation of the number of carbon atoms in the precursor ligands and silver content of the deposited structures was found. The highest silver contents were achieved for compounds with the shortest CF chains. The deposited silver content depends on the balance of electron induced ligand co-deposition and thermal ligand desorption. Low electron flux is advantageous for high silver content. Our findings demonstrate that silver carboxylates constitute a promising group of precursors for focused electron beam nanoprinting of high silver content materials.
\end{abstract}

Keywords FEBID, Nanoprinting, Silver Carboxylates

\section{Introduction}

The development of photonics and nano-optics created the need for delivering complex-shape structures with dimensions below the wavelength of visible light [1]. There are only a few methods of micro- and nano-structuring, which are able to reach this region. Most of them, like deep UV or electron-beam lithography, involve multi-step processes which apply sometimes expensive masks and are not well-adapted to creating three-dimensional structures [2]. Other techniques templateassisted electro-deposition, are able to create complex 3D-shapes like helices, but do not reach the desired resolution and size of structures [3].

Focused electron beam induced deposition (FEBID) is a direct method of growing nanostructures on any conductive substrate. It utilizes the electron beam of a scanning electron microscope (SEM) to directly deposit material in a desired shape. The gas injection system (GIS) delivers a gas of the precursor molecules from the reservoir, over the sample. The molecules adsorb 
on the surface and are locally dissociated by the electron beam. The non-volatile parts chemisorb to the substrate, creating the deposit, and the volatile ones desorb and are pumped out of the chamber. In most of the cases, FEBID is used to deposit metals from the organometallic precursors [4]. FEBID was applied in many fields including nano-magnetism [5-7], plasmonics [8], manufacturing of micro and nano-sensors $[9,10]$ and magnetic force microscopy tips [11] and photolithography masks corrections [12]

The organometallic compounds which are currently used are in most cases volatile enough to be used with the GIS at room or moderately elevated temperatures (below $200{ }^{\circ} \mathrm{C}$ ). The challenge remains to deposit as pure structures as possible, where purity is defined as the content of metal inside deposited structure in atomic percent. Due to two unwanted mechanisms: incomplete precursor dissociation and co-deposition of organic ligands, the purity of the typical material deposited with the electron beam ranges from 10 to 25 at $\%$ [4, 13, 14]. There are several methods of post-exposure purification of the deposited material. Some of them involve e-beam irradiation with the presence of water vapour $[15,16]$ or oxygen [17]. Others rely on heating either in vacuum $[6,18$, 19] or in a reactive atmosphere [20,21]. The problem is to retain the shape of the deposited structure upon purification. Although there are some exceptions [8, 22], in many cases the shape of the deposited 3D structure was not preserved, mostly due to high volume reduction caused by large contaminant content in the as-deposited material [20]. Hence, it is of crucial importance to identify new, FEBID-dedicated precursor molecules.

Silver is one of the most interesting materials for nano-photonics and plasmonics application, since it features the smallest optical losses of all metals in the visible and UV range. Under light illumination the free electron gas of silver nanostructures can be collectively excited forming so-called (sur-face) plasmon-polaritons, quasiparticles that couple light with matter excitations. Plasmons show a strongly resonant behaviour localizing light below the diffraction limit along with extraordinary enhanced fields near the metallic surface. Plasmonic nanostructures may be employed for sensing with surface enhanced Raman scattering as the most popular example [23] but, in case of commensurable losses, also for light-based information technologies [24].

Carboxylates are known as chemical vapour deposition precursors, giving high purity thin layers of metal [25-29]. Two silver and one copper carboxylates have already been examined and gave promising deposition results as FEBID precursors with metal contents of the deposits on the order of 74 and 76 at. $\%$ for $\mathrm{Ag}_{2}\left[\mu-\mathrm{O}_{2} \mathrm{CC}(\mathrm{Me})_{2} \mathrm{Et}_{2}[30]\right.$ and $\mathrm{Ag}_{2}\left[\mu-\mathrm{O}_{2} \mathrm{CC}_{2} \mathrm{~F}_{5}\right]_{2}[31]$, and on the order of 26 at.\% for $\mathrm{Cu}_{2}\left[\mu-\mathrm{O}_{2} \mathrm{CC}_{2} \mathrm{~F}_{5}\right]_{2}[21]$.

In this work, we present a comparative studies of five silver carboxylates. Three perfluorinated compounds, which differ by $\mathrm{CF}_{2}$ groups in their ligand carbon chains: $\left[\mathrm{Ag}_{2}\left(\mu-\mathrm{O}_{2} \mathrm{CCF}_{3}\right)_{2}\right],\left[\mathrm{Ag}_{2}(\mu-\right.$ $\left.\left.\mathrm{O}_{2} \mathrm{CC}_{2} \mathrm{~F}_{5}\right)_{2}\right],\left[\mathrm{Ag}_{2}\left(\mu-\mathrm{O}_{2} \mathrm{CC}_{3} \mathrm{~F}_{7}\right)_{2}\right]$ and two compounds containing : $\left[\mathrm{Ag}_{2}\left(\mu-\mathrm{O}_{2} \mathrm{CC}(\mathrm{Me})_{2} \mathrm{Et}\right)_{2}\right]$ and $\left[\mathrm{Ag}_{2}(\mu-\right.$ $\left.\mathrm{O}_{2} \mathrm{C}^{\mathrm{t} B u}\right)_{2}$ ]. In our study we focus on the influence of the $\mathrm{CF}$ or $\mathrm{CH}$ length on achieved purity and structure.

\section{Materials and Methods}

\subsection{Chemical formula and properties of silver carboxylates}

All of the investigated compounds have similar structural formulas with a dimeric form and the $\mathrm{Ag}$ atoms attached to the oxygen atoms from the carboxylate ligand. In the case of silver 2,2dimethylpropanoate and silver trifluoroacetate dimers are connected with each other by bridging Ag-O bonds [25, 32-34]. Although, as in case of FEBID, the most important is the form of subimated molecules, we present each percursor only in a form of dimer. 
a)

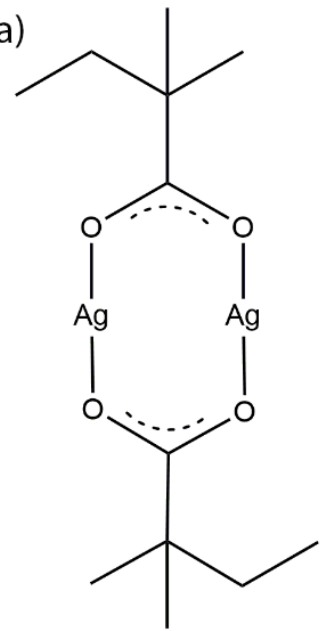

$\left[\mathrm{Ag}_{2}\left(\mu-\mathrm{O}_{2} \mathrm{CC}(\mathrm{Me})_{2} \mathrm{Et}\right)_{2}\right]$
$\mathrm{Ag}: \mathrm{O}: \mathrm{C}: \mathrm{F}: \mathrm{H}$

1:2:6:0:11 b)

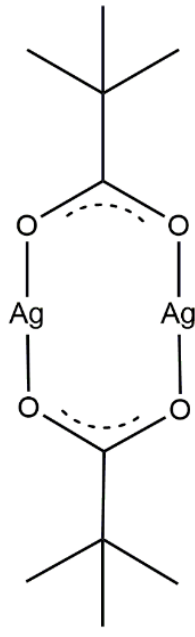

$\left[\mathrm{Ag}_{2}\left(\mu-\mathrm{O}_{2} \mathrm{C}^{\mathrm{t} B u}\right)_{2}\right]$

Ag:O:C:F:H

1:2:5:0:9<smiles>FC(F)(F)CC(F)(F)C(F)(F)C(F)(F)C(F)(F)F</smiles><smiles>FC(F)(F)C(F)(F)C(F)(F)F</smiles>

e)
[A $\mathrm{Ag}: \mathrm{O}: \mathrm{C}: \mathrm{F}: \mathrm{H}$ 1:2:4:7:0
1:2:3:5:0
Ag:O:C:F:H<smiles>FC(F)(F)C1=C(C(F)(F)F)O[Te]O[Ge]O1</smiles>

$\left[\mathrm{Ag}_{2}\left(\mu-\mathrm{O}_{2} \mathrm{CCF}_{3}\right)_{2}\right]$

Ag:O:C:F:H

1:2:2:3:0

Figure 1. Structural formulae of precursors investigated sorted with decreasing number of carbon atoms in ligands from left to right. The fluorinated silver carboxylates form a series with carbon chain lengths of two to four carbon atoms and the carboxylates containing hydrogen continue with bulk ligands of five to six carbon atoms.

All compounds are white crystalline powders that are stable in air and vacuum, which makes them easy to use in any FEBID setup. The thermal properties of the silver carboxylates were investigated earlier using vacuum thermal gravimetric analysis. The main difference between fluorinated and non-fluorinated compound is in their thermal stability. Although the mass loss starts earlier for the latter (around $180^{\circ} \mathrm{C}$ ) they exhibit significant amount of residues (even heated up in vacuum): around $45-50 \%$ of initial mass, suggesting simultaneous sublimation and thermal dissociation. In contrast, fluorinated precursors showed only few percent of mass residues, indicating, that sublimation of intact molecules is dominating over thermal decomposition [35].

\subsection{Precursor delivery}

All of the examined silver precursors have lower volatility compared to precursors typically used in the FEBID process for other metals. Precursor molecules were delivered via a customized inchamber stainless steel gas injection system (GIS) attached to a mobile three axes holder. The GIS had a final nozzle of $3 \mathrm{~mm}$ diameter to provide enough precursor molecules over the sample substrate. The GIS temperatures for the silver carboxylate FEBID were around 150 to $190{ }^{\circ} \mathrm{C}$, see table 1. For comparison, typical precursors like $(\mathrm{Me})_{3} \mathrm{PtCpMe}$ for platinum and $\mathrm{W}(\mathrm{CO})_{6}$ for tungsten require around $60{ }^{\circ} \mathrm{C}$ while for cobalt FEBID with $\mathrm{Co} 2(\mathrm{CO}) 8$ already room temperature is sufficient.

The molecule throughput $Q$ through the GIS was determined by mass loss measurements for each FEBID experiment using $\mathrm{Q}=(\Delta \mathrm{m} / \Delta \mathrm{t}) \cdot\left(\mathrm{N}_{\mathrm{A}} / \mathrm{M}\right)$, with $\Delta \mathrm{m}$ the mass loss during time $\Delta \mathrm{t}$ when the GIS was hot, $\mathrm{N}_{\mathrm{A}}$ the Avogadro number, and $\mathrm{M}$ the molecular mass of the silver carboxylate. The molecule flux impinging at the substrate was simulated by our freeware GISsimulator [36] which is documented in [37]. It takes the nozzle geometry into account to map the impinging precursor distribution on the substrate, see Fig. S1 in the supplementary information. The typical impinging molecule flux $\mathrm{J}$ in the FEBID region was about $28 \%$ of the total flux exiting the nozzle outlet area $\mathrm{A}$, i.e. $\mathrm{J} \cong(0.28) \cdot \mathrm{Q} / \mathrm{A}$. In all our experiments we used a GIS nozzle with a cylindrical inner tube cross section and an inner diameter of $3 \mathrm{~mm}$. Table 1 gathers the GIS temperatures used and related ranges of throughput and molecule flux of each silver carboxylate. 
Table 1. Summary of gas injection system (GIS) temperatures, molecule throughput $\mathrm{Q}$ through the heated GIS and impinging molecule flux J on the substrate at FEBID position for the silver carboxylates having the molar mass $\mathrm{M}$.

\begin{tabular}{|c|c|c|c|c|}
\hline Precursor & GIS $\left({ }^{\circ} \mathrm{C}\right)$ & $\begin{array}{c}\mathrm{Q} \\
\text { (molecules/s) }\end{array}$ & $\mathrm{J} \quad\left(\right.$ molecules $\left./\left(\mathrm{s} \cdot \mathrm{cm}^{2}\right)\right)$ & $\mathrm{M}(\mathrm{g} / \mathrm{mol})$ \\
\hline$\left[\mathrm{Ag}_{2}\left(\mu-\mathrm{O}_{2} \mathrm{CC}(\mathrm{Me})_{2} \mathrm{Et}\right)_{2}\right]$ & $145-175^{\circ} \mathrm{C}$ & $(0.2-11)^{*} 10^{14}$ & $(0.8-45)^{*} 10^{14}$ & 222 \\
\hline$\left[\mathrm{Ag}_{2}\left(\mu-\mathrm{O}_{2} \mathrm{C}^{\mathrm{t}} \mathrm{Bu}\right)_{2}\right]$ & $170-190^{\circ} \mathrm{C}$ & $(2.2-4.9) * 10^{14}$ & $(8.6-20)^{*} 10^{14}$ & 209 \\
\hline$\left[\mathrm{Ag}_{2}\left(\mu-\mathrm{O}_{2} \mathrm{CC}_{3} \mathrm{~F}_{7}\right)_{2}\right]$ & $175-190^{\circ} \mathrm{C}$ & $(4.4-6.0) * 10^{14}$ & $(1.7-2.4) * 10^{15}$ & 321 \\
\hline$\left[\mathrm{Ag}_{2}\left(\mu-\mathrm{O}_{2} \mathrm{CC}_{2} \mathrm{~F}_{5}\right)_{2}\right]$ & $150-180^{\circ} \mathrm{C}$ & $(3.8-5.2) * 10^{14}$ & $(1.4-2.0) * 10^{15}$ & 271 \\
\hline$\left[\mathrm{Ag}_{2}\left(\mu-\mathrm{O}_{2} \mathrm{CCF}_{3}\right)_{2}\right]$ & $170-185^{\circ} \mathrm{C}$ & $(2.8-2.9) * 10^{14}$ & $(1.1-1.2) * 10^{15}$ & 221 \\
\hline
\end{tabular}

\subsection{Deposition process}

The FEBID experiments were performed using a Hitachi S3600 SEM, equipped with a custom heating stage. The stage was usually kept at a similar temperature as the GIS and never less than 10 - $20^{\circ} \mathrm{C}$ lower than the GIS to avoid condensation of precursor molecules on the substrate. Pieces of $\mathrm{Si}<100>$ Boron p-doped wafer with native oxide layer were used as a substrate for deposit composition studies. Structures for TEM measurements were deposited directly on the silicon nitride membrane.

All square deposits were carried out at an acceleration voltage of $20 \mathrm{kV}$ (except of the one prepared with $\left[\mathrm{Ag}_{2}(\mu-\mathrm{O} 2 \mathrm{CC} 2 \mathrm{~F} 5) 2\right]$, which was made with $\left.15 \mathrm{kV}\right)$ and beam currents of 0.5-0.6 nA. Further deposition parameters in case of rectangular deposits were: $10 \mu \mathrm{m}$ side length, $1 \mu$ s dwell time, $6 \mathrm{~nm}$ point pitch, and 400 passes. All deposits were manufactured using a spiral scan strategy from the outside to the centre of the square. All spot deposits were made with the same acceleration voltage of $20 \mathrm{kV}$ and the sample current of $0.5-0.6 \mathrm{nA}$ and 5 min exposure time.

\subsection{Characterization}

The deposit morphologies were analysed using a Hitachi S4800 SEM. The compositions were measured with an energy dispersive X-ray spectroscopy (EDS) system from EDAX. A voltage of $8 \mathrm{kV}$ was chosen to provide enough intensity saturation for each measured characteristic $X$-ray line. When the thickness of the deposit was small the characteristic lines of the substrate atoms were visible. Quantification results for such spectra were corrected using the thin film SAMx StrataGEM software $[38,39]$.

Thickness profiles and topography of all deposits were measured using an atomic force microscope (AFM) from NT-MDT. The measurements were performed in semi - contact (tapping) mode using standard Si Bruker tips RTESPA-300 with a reflective back layer made with Al.

Transmission electron microscopy (TEM) structural characterization and diffraction measurements were performed in a JEOL JEM $2200 \mathrm{FS}$, operated at $200 \mathrm{kV}$ in both high resolution (HR-TEM) and scanning mode (STEM). Electron transparent SiNx membrane TEM grids were used as substrates. The thickness of the SiNx membranes was $50 \mathrm{~nm}$ and the size of each membrane window was about $100 \times 100 \mu \mathrm{m}^{2}$.

\section{Results and discussion}

\subsection{Morphology and composition of the deposits}

\subsubsection{Square deposits}

Figure 2 shows SEM images of three squares, each deposited with the same pattering strategy, but with different precursors: $\left[\mathrm{Ag}_{2}\left(\mu-\mathrm{O}_{2} \mathrm{C}\left({ }^{(} \mathrm{Bu}\right)_{2}\right]\right.$ Fig2.a, $\left[\mathrm{Ag}_{2}\left(\mu-\mathrm{O}_{2} \mathrm{CC}(\mathrm{Me})_{2} \mathrm{Et}\right)_{2}\right]$ Fig2.b, $\left[\mathrm{Ag}_{2}(\mu-\right.$ $\left.\left.\mathrm{O}_{2} \mathrm{CCF}_{3}\right)_{2}\right]$ Fig2.c, $\left[\mathrm{Ag}_{2}\left(\mu-\mathrm{O}_{2} \mathrm{CC}_{2} \mathrm{~F}_{5}\right)_{2}\right]$ Fig2.d, $\left[\mathrm{Ag}_{2}\left(\mu-\mathrm{O}_{2} \mathrm{CC}_{3} \mathrm{~F}_{7}\right)_{2}\right]$ Fig2.e. The morphology of the square deposits is granular with a rough surface. The average particle size is largest for $\left[\mathrm{Ag}_{2}\left(\mathrm{O}_{2} \mathrm{CC}_{3} \mathrm{~F}_{7}\right)_{2}\right]$ (Fig. 2.e). Despite this, there is no clear correlation between particle size and number of carbon atoms in 
the precursor molecules. There is also no huge difference in morphology between fluorinated and non-fluorinated carboxylates. Basing on the average thickness of the deposits, measured using AFM and the deposition time, growth rates of square deposits were estimated. The values span from 0.9 $\AA / s$ for both $\left[\mathrm{Ag}_{2}\left(\mathrm{O}_{2} \mathrm{CC}_{3} \mathrm{~F}_{7}\right)_{2}\right]$ and $\left[\mathrm{Ag}_{2}\left(\mu-\mathrm{O}_{2} \mathrm{CC}(\mathrm{Me})_{2} \mathrm{Et}\right)_{2}\right]$, through $1.4 \AA / \mathrm{s}$ for $\left[\mathrm{Ag}_{2}\left(\mu-\mathrm{O}_{2} \mathrm{CCF}_{3}\right)_{2}\right], 2.1$ $\AA / \mathrm{s}$ for $\left[\mathrm{Ag}_{2}\left(\mu-\mathrm{O}_{2} \mathrm{C}\left({ }^{\mathrm{t}} \mathrm{Bu}\right)_{2}\right]\right.$ up to $2.8 \AA / \mathrm{s}$ for $\left[\mathrm{Ag}_{2}\left(\mu-\mathrm{O}_{2} \mathrm{CC}_{2} \mathrm{~F}_{5}\right)_{2}\right]$. There is also no strict correlation between number of carbon atoms in (and the size of) ligand and the growth rate. The highest growth rate exhibits $\left[\mathrm{Ag}_{2}\left(\mu-\mathrm{O}_{2} \mathrm{CC}_{2} \mathrm{~F}_{5}\right)_{2}\right]$, the only one, for which three-dimensional growth could be demonstrated up to now.40 Blue, dashed lines shows the nominal $10 \times 10 \mu \mathrm{m}^{2}$ area, programmed with the patterning software. What can be noticed is that the side length of each deposited square is visibly higher than $10 \mu \mathrm{m}$. But one has to remember that the size of the electron beam is not negligible and was determined to be around $450 \mathrm{~nm}$ (full beam width within which $99 \%$ of electrons are contained - FW99). Moreover, in all previously reported cases, deposits made with silver carboxylates had significant halos - material deposited around the actual irradiation spot, due to interactions of secondary electrons of second type (SE II) with adsorbed precursor molecules [30, 31, 40]. More detailed discussion about halos can be found in the next section of this work.

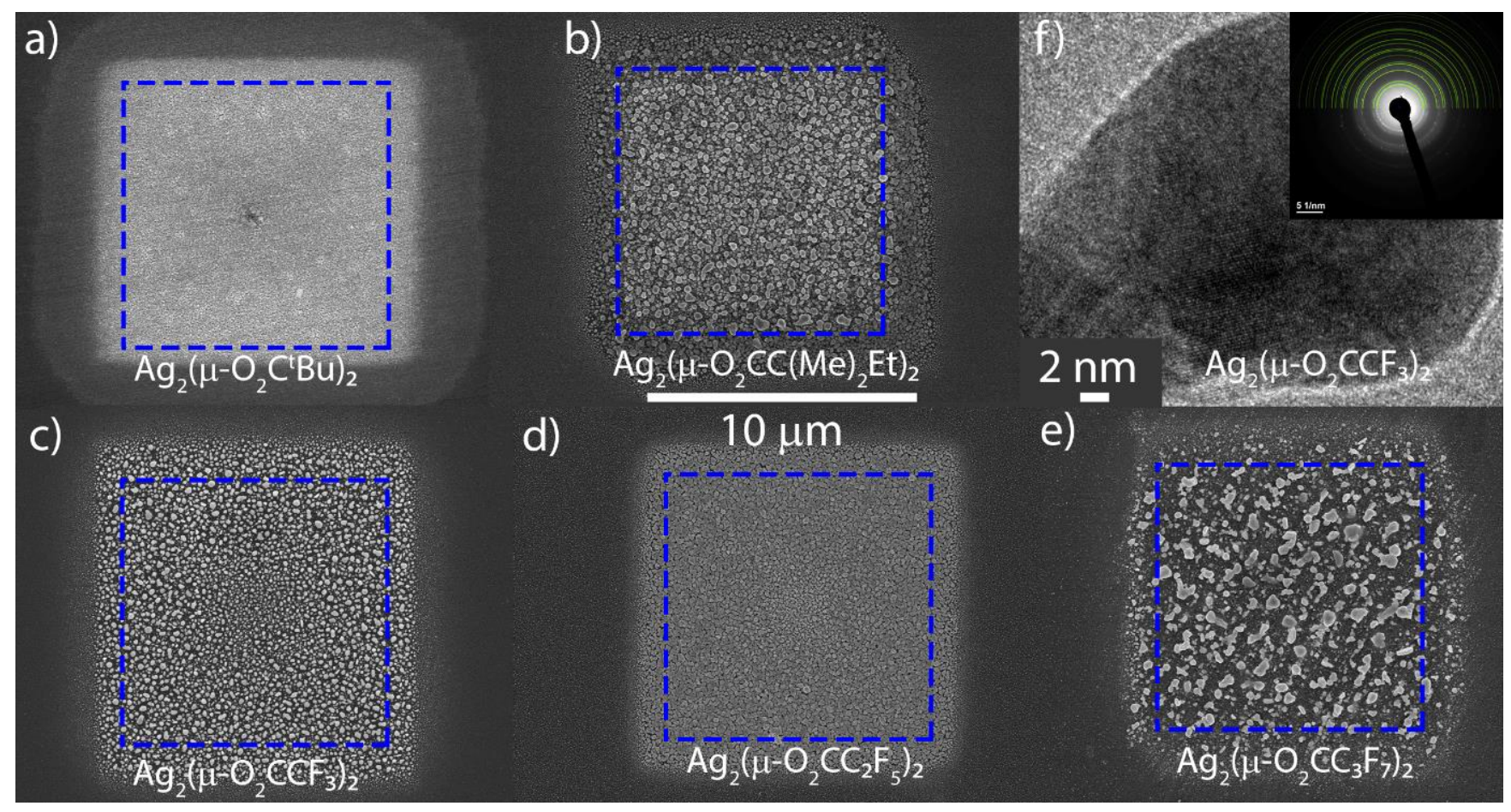

Figure 2. Overview of SEM top view images of FEBID square deposits of $10 \times 10 \mu \mathrm{m} 2$ from different silver carboxylates. a-b) show carboxylates containing hydrogen, c-e) show the fluorinated carboxylates. f) HR-TEM image of an individual silver particle made with $\left[\mathrm{Ag}_{2}\left(\mu-\mathrm{O}_{2} \mathrm{CCF}_{3}\right)_{2}\right]$; comparable particles were found also for $\left[\mathrm{Ag}_{2}\left(\mathrm{O}_{2} \mathrm{CC}_{3} \mathrm{~F}_{7}\right)_{2}\right]$ and $\left[\mathrm{Ag}_{2}\left(\mu-\mathrm{O}_{2} \mathrm{CC}(\mathrm{Me})_{2} \mathrm{Et}\right)_{2}\right]$; diffraction inset indicates pure silver grains by indexing.

All carboxylates provide a maximum amount of silver in the deposit above 50 at. \%. This is high considering the typical values of 15-25 at.\% for commercially available platinum and tungsten precursors $[4,15,41]$. The highest value of 74 at. $\% \mathrm{Ag}$ was achieved using $\left[\mathrm{Ag}_{2}\left(\mu-\mathrm{O}_{2} \mathrm{CCF}_{3}\right)_{2}\right]$. The EDX signal was gathered by scanning over square areas of around $1 \times 1 \mu \mathrm{m} 2$, which were positioned at least $1.5 \mu \mathrm{m}$ away from the edge of the deposit, to avoid signal collection from Si not covered with deposit. Per silver carboxylate precursor at least 4 FEBID squares written with identical deposition conditions were measured with their average and best-of values reported in table. 2 .

Table 2. Summary of stoichiometry of examined silver carboxylates in comparison to average and best-of atomic ratio and the best achieved metal content of deposited square structures. The best-of 
carbon removal values were calculated as $1-\mathrm{C}_{\mathrm{dep}} / \mathrm{C}_{\mathrm{prec}}$, where $\mathrm{C}_{\mathrm{dep}}$ stands for carbon content in deposit and $\mathrm{C}_{\text {prec }}$ carbon content in pristine precursor molecule.

\begin{tabular}{|c|c|c|c|c|c|}
\hline Precursor & $\begin{array}{c}\text { Precursor } \\
\text { Stoichiometry } \\
\text { Ag:O:C:F:H }\end{array}$ & $\begin{array}{l}\text { Atomic ratio } \\
\text { of best purity } \\
\text { Ag:O:C:F:(H*) }\end{array}$ & $\begin{array}{c}\text { Best Ag } \\
\text { (at\%) }\end{array}$ & C removal & $\begin{array}{c}\text { Atomic ratio } \\
\text { average } \\
\text { Ag:O:C:F:(H*) }\end{array}$ \\
\hline $\begin{array}{c}{\left[\mathrm{Ag}_{2}(\mu-\right.} \\
\left.\left.\mathrm{O}_{2} \mathrm{CC}(\mathrm{Me})_{2} \mathrm{Et}\right)_{2}\right]\end{array}$ & $1: 2: 6: 0: 11$ & $\begin{array}{c}\text { 1: } 0.08: 0.51: 0: \\
(0.11)\end{array}$ & 59 & $91 \%$ & 1:0.10:0.57:0:(0.13) \\
\hline $\begin{array}{c}{\left[\mathrm{Ag}_{2}(\mu-\right.} \\
\left.\left.\mathrm{O}_{2} \mathrm{C}^{t} \mathrm{Bu}\right)_{2}\right]\end{array}$ & 1:2:5:0:9 & $\begin{array}{c}1: 0.08: 0.57: 0: \\
(0.12)\end{array}$ & 57 & $89 \%$ & 1:0.07:0.75:0:(0.17) \\
\hline $\begin{array}{c}{\left[\mathrm{Ag}_{2}(\mu-\right.} \\
\left.\left.\mathrm{O}_{2} \mathrm{CC}_{3} \mathrm{~F}_{7}\right)_{2}\right]\end{array}$ & 1:2:4:7:0 & 1: $0: 0.52: 0.22$ & 57 & $87 \%$ & 1:0.02:0.91:0.40 \\
\hline $\begin{array}{c}{\left[\mathrm{Ag}_{2}(\mu-\right.} \\
\left.\left.\mathrm{O}_{2} \mathrm{CC}_{2} \mathrm{~F}_{5}\right)_{2}\right]\end{array}$ & 1:2:3:5:0 & $\begin{array}{c}\text { 1: } 0.04: 0.27: \\
0.11\end{array}$ & 70 & $91 \%$ & 1:0.08:0.41:0.10 \\
\hline $\begin{array}{c}{\left[\mathrm{Ag}_{2}(\mu-\right.} \\
\left.\left.\mathrm{O}_{2} \mathrm{CCF}_{3}\right)_{2}\right]\end{array}$ & 1:2:2:3:0 & $\begin{array}{c}1: 0.02: 0.29: \\
0.03\end{array}$ & 74 & $86 \%$ & 1:0.03:0.36:0.04 \\
\hline
\end{tabular}

${ }^{*} \mathrm{H}$ is not detectable using EDX method; numbers given in parentheses were estimated, using C:H ratio of 9:2. For explanation, see text.

The most interesting observation from table 2 is that the oxygen content in all the best-of deposits is very low; the Ag:O ratio increases from 1:2 within the precursors to values between 1:0 and 1:0.08. This hints to an efficient dissociation of the silver-ligand bonds, i.e. the silver-oxygen bonds, in all silver carboxylates by the electrons. After dissociation the ligands reside individually on the surface until they thermally desorb or until they are further dissociated by successive electrons into nonvolatile carbon and volatile $\mathrm{CO}_{x}, \mathrm{CH}_{x}$ or $\mathrm{CF}_{x}$ moieties. To this respect the $\mathrm{Ag}: \mathrm{C}$ ratio is informative. According to table 2 for each deposit the measured best-of Ag:C ratios drop to about 9 to $14 \%$ of their initial stoichiometric Ag:C ratios in the corresponding silver carboxylate precursors. The measured $\mathrm{Ag}: \mathrm{F}$ ratios within the FEBID square deposits drop to roughly $1 \%$ to $3 \%$ of the initial precursor Ag:F ratios indicating an efficient removal of fluorine. From table 2 it can be seen that for the longest fluorinated carbon chain precursor $\left[\mathrm{Ag}_{2}\left(\mu-\mathrm{O}_{2} \mathrm{CC}_{3} \mathrm{~F}_{7}\right)_{2}\right]$, the remaining organic matrix has a composition which can be described by the sum formula $\mathrm{CF}_{0.5}$ while for the shorter fluorinated carbon chain silver carboxylates the organic matrix is mainly carbon, doped with fluorine at a much lower concentration. Figure 3 shows the absolute atomic percent composition derived from the results from table 2. The highest metal content in the perfluorinated silver carboxylates (both average and best recorded) was observed for the shortest chain ligand $\mathrm{O}_{2} \mathrm{CCF}_{3}$ and decreases when adding CF2 groups to the ligand, see Fig. 3. In an attempt to estimate the hydrogen content in table 2 and Fig. 3, we recall room temperature FEBID experiments with volatile organic compounds by Bret et al., who found a ratio of $\mathrm{C}: \mathrm{H}=9: 2(\mathrm{CH} \approx 0.2)$ in the deposits by elastic recoil detection analysis. It has to be mentioned that the EDX quantification was performed without a standard and that carbon quantification is impeded by the residual hydrocarbons present in the vacuum chamber of the measurement system. Hence, the obtained silver-to-carbon ratios in table 2 and figure 3 can be taken as a lower limit. 


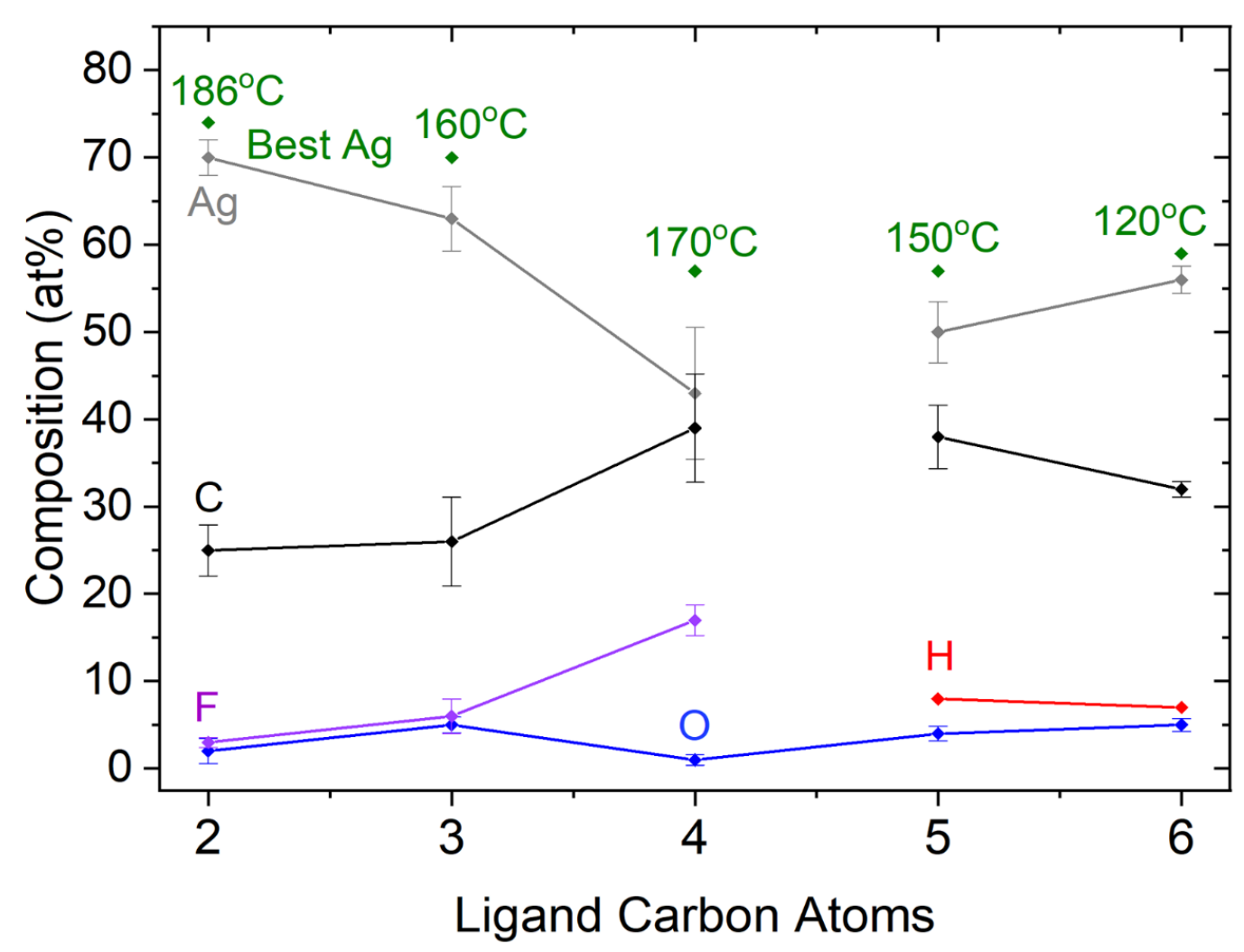

Figure 3. Composition of square deposits (average and best achieved) vs number of carbon atoms in the ligand of the pristine precursor molecules. H was estimated using C:H ratio of 9:2. For explanation, see text. Numbers above the best purity points represents the stage temperatures registered for the samples with purest deposits for each precursor.

Efficient thermal desorption of the cleaved ligands also depends on substrate temperature in addition to the volatility of the ligand. The minimum substrate temperatures are given by the condensation of the individual precursors which need to be evaporated from the gas injection system at a practical flux, i.e. the GIS temperature determines the minimum substrate temperature. In Fig. 4 the stage temperatures are indicated. Similar to the dependence between purity and number of ligand carbon atoms, there is only slight correlation between best achieved purity and the stage temperature used during FEBID experiment. The highest silver content of the smallest ligand carboxylate can thus be attributed to either high substrate temperature or high $\left(\mu-\mathrm{O}_{2} \mathrm{CCF}_{3}\right)$ volatility or both. On the contrary, for both non-fluorinated compounds, where the stage temperature was significantly lower, also the best achieved silver contents were lower. Desorption of physisorbed species is a process driven by temperature. Highest purity achieved for $\left[\mathrm{Ag}_{2}\left(\mu-\mathrm{O}_{2} \mathrm{CCF}_{3}\right)_{2}\right]$, where the highest stage temperature was used may suggest, that, for this precursor, thermal desorption of ligands was the most efficient. Moreover it may explain the lower purity of deposits made with $\left[\mathrm{Ag}_{2}\left(\mu-\mathrm{O}_{2} \mathrm{CC}_{3} \mathrm{~F}_{7}\right)_{2}\right]$. Although the stage temperature was high, the cleaved ligand was heavy, and its desorption time was may not have been not short enough so for it could to leave the substrate without further dissociation and incorporation inside the deposit.

To confirm if the silver - oxygen bonds have been effectively cleaved, transmission electron microscope measurements were performed on a series of spot and line deposits on a $\mathrm{SiN}_{\mathrm{x}}$ membrane. Each time the thickest, yet still transparent, spot and line were chosen for measurements.

Representative HR TEM image (Fig. 2.f) of single grains from the deposits exhibit regions with parallel atomic planes, indicating a crystalline structure of deposited material. Diffraction studies, 
performed on both line and spot deposits show that measured patterns match that of pure silver, in the case of all measured precursors. The inset of Fig.2.f presents an exemplary pattern from a spot deposit made with $\left[\mathrm{Ag}_{2}\left(\mu-\mathrm{O}_{2} \mathrm{CCF}_{3}\right)_{2}\right]$. Green rings visible in the upper part of the diffraction patterns correspond to the expected diffraction ring positions for pure silver, taken from the database of CSpot software. Patterns measured on deposits made with $\left[\mathrm{Ag}_{2}\left(\mu-\mathrm{O}_{2} \mathrm{CC}(\mathrm{Me})_{2} \mathrm{Et}\right)_{2}\right]$ and $\left[\mathrm{Ag}_{2}\left(\mu-\mathrm{O}_{2} \mathrm{CC}_{3} \mathrm{~F} 7\right)_{2}\right]$ with matching silver rings are available in the Supporting Information. Measured patterns for each precursor were also compared to the ring patterns of pure $\mathrm{Ag} 2 \mathrm{O}$, but they did not match (cf. Supporting Information for further details).

The TEM data proves that in each case the material deposited with the electron beam from silver carboxylates forms pure silver crystals. Hence for each carboxylate the Ag-O bond is most probably cleaved due to electron irradiation. Carbon, and in some cases fluorine, which was detected with EDX, were co-deposited in-between the silver crystals. The same behaviour was reported before for [Ag2 $\left.\left(\mu-\mathrm{O}_{2} \mathrm{CC}_{2} \mathrm{~F}_{5}\right)_{2}\right][31]$ and $\left[\mathrm{Ag}_{2}\left(\mu-\mathrm{O}_{2} \mathrm{CC}(\mathrm{Me})_{2} \mathrm{Et}\right)_{2}\right][30]$.

This resembles the inner structure of deposits from other metal-organic precursor compounds, where crystalline grains are embedded in a carbonaceous matrix. However, only in the case of silver carboxylates does the crystal formation become dominant over the co-deposition of ligands and residual hydrocarbons from the vacuum background. Therewith, silver carboxylates provide the exciting prospect of realizing high-purity deposits that are otherwise only achievable using unstable inorganic precursor compounds [42]. There are several reasons for the unusually pure metal deposition. First, all silver carboxylates exhibit only one ligand to be cleaved, and this ligand is weakly bound [40 More importantly, the elevated temperature of both molecules and substrate introduces additional kinetic energy into the electron induced dissociation process, which may be therefore considered as 'thermally assisted'. Furthermore, the heated substrate drives surface diffusion and enhances desorption of molecules and the cleaved ligands. This may decrease the overall deposition efficiency by causing small residence times of precursor molecules [43] but it also increases desorption of cleaved ligands and thus hinders the co-deposition of carbon. It may be the reason of the highest purity obtained for $\left[\mathrm{Ag}_{2}\left(\mu-\mathrm{O}_{2} \mathrm{CCF}_{3}\right)_{2}\right]$, where the highest stage temperature of $186^{\circ} \mathrm{C}$ was used. Additionally, surface diffusion of metal atoms and clusters results in an efficient growth of metal particles due to Ostwald ripening [44]

\subsubsection{Spot deposits}

To further study the deposition process with respect to the balance of arriving molecules and electrons, spot deposits were performed with all silver carboxylates. As the electron flux decreases radially from the centre to the outside by orders of magnitude the maximum possible dissociation rate, being the product of the dissociation cross section and the radial electron flux, does so too. In other words, the FEBID regimes change radially between mass-transport limited, desorption limited, and reaction limited. Implications on the FEB deposition rate were reviewed in a paper from SanzHernandez et al [45]. Another implication of the changing rate ratio of dissociation versus desorption is the composition. Based on FEBID experiments with $\left[\mathrm{Ag}_{2}\left(\mu-\mathrm{O}_{2} \mathrm{CC}(\mathrm{Me})_{2} \mathrm{Et}\right)_{2}\right]$, it was proposed that in the centre of the beam the carboxylate ligands co-dissociate as their desorption rate is low compared to their co-dissociation rate [30]. At larger radii - in the halo region - the relation of rates inverses and the ligands have enough time to desorb before they are co-deposited [30,31]. This explains the lower silver content in the centre with respect to the outside halo.

As can be seen in Fig. 4, the common feature for all carboxylate deposits is a visible halo deposit. For the aforementioned platinum, tungsten, and cobalt precursors such halo deposits are very thin and almost not visible. The halo is created due to dissociation of adsorbed precursor molecules by second type secondary electrons (SE II) coming from the interaction between the substrate and backscattered electrons (BSE). The green, dotted ring in the middle of each deposit represents the measured beam size (full width containing 99\% of electrons), which was around $450 \mathrm{~nm}$. Monte Carlo simulations with CASINO [46] result in radial BSE flux profiles shown in Fig. 4f. The calculated flux at the outermost SEM-visible halo is marked for each deposit in Fig. 4. In comparison, the peak flux 
value given by the SE generation of the primary electron beam at the centre was $3.6 \cdot 10^{3}$ electrons $/\left(\mathrm{nm}^{2} \cdot \mathrm{s}\right)$ for all our FEB deposits. Larger halo diameters indicate a larger electron sensitivity with respect to deposition of non-volatile moieties, including both the silver carboxylate (resulting in silver deposit) and the carboxylate ligand (resulting in carbon deposit with traces of fluorine or hydrogen).

However, in the case of silver carboxylates, there is a significant amount of material deposited in the halo region. In some cases it is hard to distinguish the halo region from the central part of the deposit in the AFM profiles. (All AFM profiles are given in the SI.) Only for three precursors $\left[\mathrm{Ag}_{2}(\mu-\right.$ $\left.\left.\mathrm{O}_{2} \mathrm{C}^{\mathrm{t} B u}\right)_{2}\right],\left[\mathrm{Ag}_{2}\left(\mu-\mathrm{O}_{2} \mathrm{CCF}_{3}\right)_{2}\right]$ and $\left[\mathrm{Ag}_{2}\left(\mu-\mathrm{O}_{2} \mathrm{CC}_{2} \mathrm{~F}_{5}\right)_{2}\right]$, the centre is visibly thicker than the halo. This hints to a strong depletion of precursor molecules in the central region of the deposit what may be a consequence of the elevated stage temperatures and the resulting small residence times of the molecules.

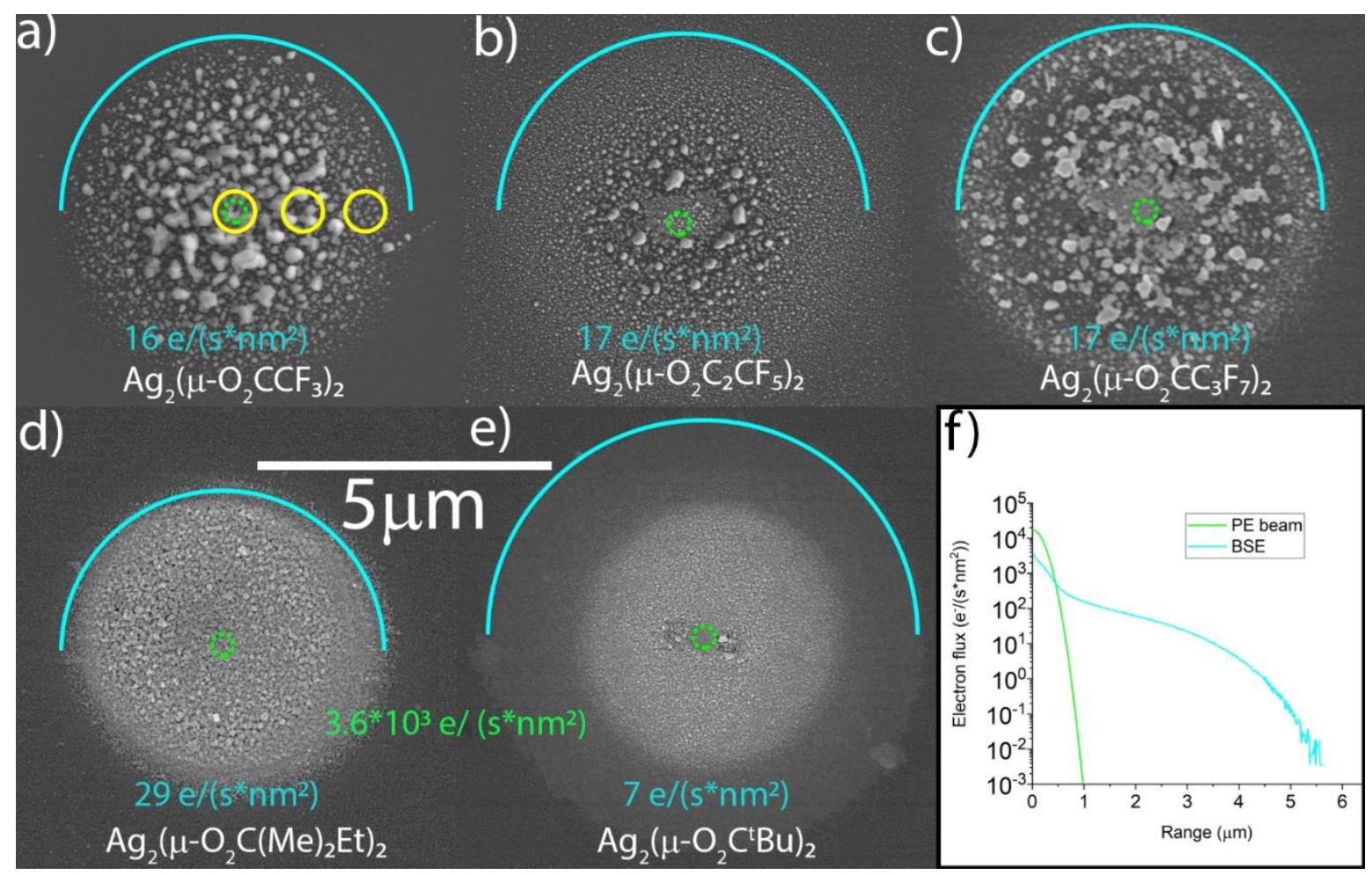

Figure 4 SEM top view images of FEBID spots taken at $8 \mathrm{keV}$. Irradiation was with $20 \mathrm{kV}$ for $5 \mathrm{~min}$. using different silver carboxylates, top: silver carboxylates containing hydrogen and bottom fluorinated silver carboxylates. Precursors are indicated. The primary electron beam (FW99) and the visible halo periphery are indicated by green and light-blue circles, respectively. Correspondingly coloured electron flux values were calculated from the Monte Carlo simulated BSE profile in $4 \mathrm{f}$. Yellow circles indicate the spots were EDX measurements were taken. Size of the circles corresponds to maximum EDX excitation range. Note that there was a slight drift in (d).

What can we see from Fig. 4 is that the morphology of the halo differs significantly between different carboxylates. As a rule of thumb, deposits made using carboxylates with hydrogen have more homogenous halo regions. They contain particles, but the particle sizes do not differ much along the halo radii. On the other hand, for perfluorinated species, we can clearly see the change of the particle size within the halo region.

The common feature of all deposits is that in the place of the highest lateral electron density (where the primary beam is) grains of deposited material are visibly smaller and that the silver content is higher in the halo region, although in the case of $\left[\mathrm{Ag}_{2}\left(\mu-\mathrm{O}_{2} \mathrm{CCF}_{3}\right)_{2}\right]$, the difference in $\mathrm{Ag}$ content is slight. This is in line with our previous studies of $\left[\mathrm{Ag}_{2}\left(\mu-\mathrm{O}_{2} \mathrm{CC}_{2} \mathrm{~F}_{5}\right)_{2}\right][31]$, and $\left[\mathrm{Ag}_{2}(\mu-\right.$ 
$\left.\mathrm{O}_{2} \mathrm{CC}(\mathrm{Me})_{2} \mathrm{Et}\right)_{2}$ ] [30]. A further common feature is the lower silver content of the periphery regions. This can be explained by the different deposition regimes along the radius of the halo. In the central region, where the primary beam is placed, the density of electrons is highest and ligand fragments may not have enough time to desorb before they are co-deposited. The halo region, with lower surface density of SEs and BSEs, balances electron driven ligand co-deposition rates and ligand fragment desorption rates leaving purer deposited material. In the peripheral region, there is most probably not enough electrons to fully dissociate the precursor molecules.

Table 3. Summary of atomic ratios of spot deposits, measured by EDX in 3 places, see Fig. 4.

\begin{tabular}{cccc}
\hline $\mathrm{Ag}: \mathrm{O}: \mathrm{C}: \mathrm{F}$ & Centre & Halo & Peripheries \\
\hline $\mathrm{Ag}_{2}(\mu-$ & $42: 7: 51: 0^{*}$ & $70: 7: 23^{*}$ & --- \\
$\left.\left.\mathrm{O}_{2} \mathrm{CC}(\mathrm{Me})_{2} \mathrm{Et}\right)_{2}\right]$ & & & \\
{$\left[\mathrm{Ag}_{2}(\mu-\right.$} & $38: 7: 55: 0$ & $65: 33: 2: 0$ & $43: 12: 45: 0$ \\
$\left.\left.\mathrm{O}_{2} \mathrm{C}^{\mathrm{BBu}}\right)_{2}\right]$ & & & \\
{$[\mathrm{Ag} 2(\mu-$} & $50: 0: 49: 1$ & $60: 0: 39: 1$ & $58: 0: 41: 1$ \\
$\left.\left.\mathrm{O}_{2} \mathrm{CC}_{3} \mathrm{~F}_{7}\right)_{2}\right]$ & & & \\
{$\left[\mathrm{Ag}_{2}(\mu-\right.$} & $45: 1: 51: 3$ & $46: 0: 51: 3$ & $35: 1: 58: 6$ \\
$\left.\left.\mathrm{O}_{2} \mathrm{CC}_{2} \mathrm{~F}_{5}\right)_{2}\right]$ & & & \\
{$\left[\mathrm{Ag}_{2}(\mu-\right.$} & $73: 0: 27: 0$ & $76: 0: 24: 0$ & $56: 0: 43: 1$ \\
$\left.\left.\mathrm{O}_{2} \mathrm{CCF}_{3}\right)_{2}\right]$ & & & \\
\hline
\end{tabular}

"Values taken from Höflich et al.30

\section{Conclusions}

Silver structures were deposited with focused electron beam induced deposition using five different carboxylates, three fluorinated: $\left[\mathrm{Ag} 2\left(\mu-\mathrm{O}_{2} \mathrm{CC}_{3} \mathrm{~F}_{7}\right)_{2}\right],\left[\mathrm{Ag}_{2}\left(\mu-\mathrm{O}_{2} \mathrm{CC}_{2} \mathrm{~F}_{5}\right)_{2}\right],\left[\mathrm{Ag}_{2}\left(\mu-\mathrm{O}_{2} \mathrm{CCF}_{3}\right)_{2}\right]$ and two non-fluorinated: $\left[\mathrm{Ag}_{2}\left(\mu-\mathrm{O}_{2} \mathrm{CC}(\mathrm{Me})_{2} \mathrm{Et}\right)_{2}\right]$ and $\left[\mathrm{Ag}_{2}\left(\mu-\mathrm{O}_{2} \mathrm{C}^{t} \mathrm{Bu}\right)_{2}\right]$. All of the compounds were very sensitive to electron dissociation The deposited materials showed high FEBID silver content above 42 at.\% up to above 70at.\% and formed pure silver crystals of even hundreds of nanometres with impurities of carbon and fluorine incorporated between met-al grains. There is correlation between the number of carbon atoms in the precursor ligands and silver content of the deposited structures. The highest silver contents were achieved for com-pounds with shortest CF chains. Temperature and electron beam flux also influence the silver content via the rate balance of electron induced ligand codeposition and ligand desorption. The halo regions investigated on purpose in this article can be reduced to less than ten nanometres using low primary electron energies. Efficient cleavage of Ag-O bonds as well as removal of the majority of the carbon and fluorine from pristine precursor molecules make these silver carboxylates a promising group of precursors for plasmonic pattern nano-printing.

Supplementary Materials: The following are available online at www.mdpi.com/xxx/s1, S1. Distribution of the impinging flux of precursor molecules as a fraction of the flux leaving nozzle exit; S2. Comparison between measured SAED patterns and the ones of pure Ag and $\mathrm{AgO}$; S3. AFM of the spot deposits

Author Contributions: Conceptualization, JJ, KH, LB and IU; methodology, JJ, LB, KH, IU, KM; validation, JJ, LB, LBr, IU.; formal analysis, JJ, LB, LBr; investigation, JJ, LB, LBr, KM, KH, TEJE.; resources, KM, ISz.; data curation, JJ, IU.; writing-original draft preparation, JJ, KM (figure 1).; writing-review and editing, ALL AUTHORS.; supervision, IU, CzK, ISz, .; project administration, IU, CzK.; funding acquisition, IU, ISz, TEJE, KH . All authors have read and agreed to the published version of the manuscript.

Funding: J.J and I.U research was conducted with the financial support of EU Horizon 2020 Marie CurieSklodowska Innovative Training Network “ELENA”, grant agreement No 722149.

T.E.J.E. received funding from EMPAPOSTDOCS-II of the European Union's Horizon 2020 research and innovation programme under the Marie Skłodowska-Curie grant agreement number 754364 .

L.B. received support from Swiss National Science Foundation (SNF) project 200021E- 
164211;

I.Sz. and K. M. received support from Nicolaus Copernicus University in Toruń (Statute

Research no.103);

K.H. acknowledges the financial support by the Deutsche Forschungsgemeinschaft (DFG) under grant no. HO 5461/3-1.

Conflicts of Interest: The authors declare no conflict of interest. The funders had no role in the design of the study; in the collection, analyses, or interpretation of data; in the writing of the manuscript, or in the decision to publish the results.

\section{References}

1. Schuller, J. A.; Barnard, E. S.; Cai, W.; Jun, Y. C.; White, J. S.; Brongersma, M. L., Plasmonics for extreme light concentration and manipulation. Nat. Mater. 2010, 9 (3), 193-204.

2. Bordonaro, G. J., DUV Photolithography and Materials. In Encyclopedia of Nanotechnology, Bhushan, B., Ed. Springer Netherlands: Dordrecht, 2012; pp 590-604.

3. Schürch, P.; Ramachandramoorthy, R.; Pethö, L.; Michler, J.; Philippe, L., Additive manufacturing by template-assisted 3D electrodeposition: Nanocrystalline nickel microsprings and microspring arrays. Appl. Mater. Today 2020, 18, 100472.

4. Huth, M.; Porrati, F.; Dobrovolskiy, O. V., Focused electron beam induced deposition meets materials science. Microelectron. Eng. 2018, 185-186, 9-28.

5. Keller, L.; Al Mamoori, M. K. I.; Pieper, J.; Gspan, C.; Stockem, I.; Schröder, C.; Barth, S.; Winkler, R.; Plank, H.; Pohlit, M.; Müller, J.; Huth, M., Direct-write of free-form building blocks for artificial magnetic 3D lattices. Sci. Rep. 2018, 8 (1), 6160.

6. Puydinger dos Santos, M. V.; Velo, M. F.; Domingos, R. D.; Zhang, Y.; Maeder, X.; GuerraNuñez, C.; Best, J. P.; Béron, F.; Pirota, K. R.; Moshkalev, S.; Diniz, J. A.; Utke, I., AnnealingBased Electrical Tuning of Cobalt-Carbon Deposits Grown by Focused-Electron-Beam-Induced Deposition. ACS Appl. Mater. Interfaces 2016, 8 (47), 32496-32503.

7. Fernández-Pacheco, A.; Streubel, R.; Fruchart, O.; Hertel, R.; Fischer, P.; Cowburn, R. P., Threedimensional nanomagnetism. Nat. Commun. 2017, 8 (1), 15756.

8. Winkler, R.; Schmidt, F.-P.; Haselmann, U.; Fowlkes, J. D.; Lewis, B. B.; Kothleitner, G.; Rack, P. D.; Plank, H., Direct-Write 3D Nanoprinting of Plasmonic Structures. ACS Appl. Mater. Interfaces 2017, 9 (9), 8233-8240.

9. Gabureac, M.; Bernau, L.; Utke, I.; Boero, G., Granular Co-C nano-Hall sensors by focused-beaminduced deposition. Nanotechnology 2010, 21 (11), 115503.

10. Arnold, G.; Winkler, R.; Stermitz, M.; Orthacker, A.; Noh, J.-H.; Fowlkes, J. D.; Kothleitner, G.; Huth, M.; Rack, P. D.; Plank, H., Tunable 3D Nanoresonators for Gas-Sensing Applications. Adv. Funct. Mater. 2018, 28 (19), 1707387.

11. Utke, I.; Cicoira, F.; Jaenchen, G.; Hoffmann, P.; Scandella, L.; Dwir, B.; Kapon, E.; Laub, D.; Buffat, P.; Xanthopoulos, N.; Mathieu, H. J., Focused Electron Beam Induced Deposition of High Resolution Magnetic Scanning Probe Tips. MRS Proceedings 2001, 706, Z9.24.1.

12. Bret, T.; Hofmann, T.; Edinger, K., Industrial perspective on focused electron beam-induced processes. Appl. Phys. A: Materi. Sci. Process. 2014, 117 (4), 1607-1614.

13. Botman, A.; Mulders, J. J. L.; Hagen, C. W., Creating pure nanostructures from electron-beaminduced deposition using purification techniques: a technology perspective. Nanotechnology 2009, 20 (37), 372001.

14. Utke, I.; Hoffmann, P.; Melngailis, J., Gas-assisted focused electron beam and ion beam processing and fabrication. J. Vac. Sci. Technol. B Microelectron. Nanom. Struct. 2008, 26.

15. Geier, B.; Gspan, C.; Winkler, R.; Schmied, R.; Fowlkes, J. D.; Fitzek, H.; Rauch, S.; Rattenberger, J.; Rack, P. D.; Plank, H., Rapid and Highly Compact Purification for Focused Electron Beam Induced Deposits: A Low Temperature Approach Using Electron Stimulated H2O Reactions. J. Phys. Chem. C 2014, 118 (25), 14009-14016.

16. Shawrav, M. M.; Taus, P.; Wanzenboeck, H. D.; Schinnerl, M.; Stöger-Pollach, M.; Schwarz, S.; Steiger-Thirsfeld, A.; Bertagnolli, E., Highly conductive and pure gold nanostructures grown by electron beam induced deposition. Sci. Rep. 2016, 6, 34003. 
17. Plank, H.; Noh, J. H.; Fowlkes, J. D.; Lester, K.; Lewis, B. B.; Rack, P. D., Electron-Beam-Assisted Oxygen Purification at Low Temperatures for Electron-Beam-Induced Pt Deposits: Towards Pure and High-Fidelity Nanostructures. ACS Appl. Mater. Interfaces 2014, 6 (2), 1018-1024.

18. Puydinger dos Santos, M. V.; Szkudlarek, A.; Rydosz, A.; Guerra-Nuñez, C.; Béron, F.; Pirota, K. R.; Moshkalev, S.; Diniz, J. A.; Utke, I., Comparative study of post-growth annealing of $\mathrm{Cu}(\mathrm{hfac}) 2$, $\mathrm{Co} 2(\mathrm{CO}) 8$ and $\mathrm{Me} 2 \mathrm{Au}(\mathrm{acac})$ metal precursors deposited by FEBID. Beilstein J. Nanotech. 2018, 9, 91-101.

19. Szkudlarek, A.; Rodrigues Vaz, A.; Zhang, Y.; Rudkowski, A.; Kapusta, C.; Erni, R.; Moshkalev, S.; Utke, I., Formation of pure $\mathrm{Cu}$ nanocrystals upon post-growth annealing of $\mathrm{Cu}-\mathrm{C}$ material obtained from focused electron beam induced deposition: comparison of different methods. Beilstein J. Nanotech. 2015, 6, 1508-1517.

20. Jurczyk, J.; Brewer, C. R.; Hawkins, O. M.; Polyakov, M. N.; Kapusta, C.; McElwee-White, L.; Utke, I., Focused Electron Beam-Induced Deposition and Post-Growth Purification Using the Heteroleptic Ru Complex (†3-C3H5)Ru(CO)3Br. ACS Appl. Mater. Interfaces 2019, 11 (31), 28164-28171.

21. Berger, L.; Jurczyk, J.; Madajska, K.; Edwards, T. E. J.; Szymańska, I.; Hoffmann, P.; Utke, I., High-Purity Copper Structures from a Perfluorinated Copper Carboxylate Using Focused Electron Beam Induced Deposition and Post-Purification. ACS Appl. Electron. Mater. 2020, 2 (7), 1989-1996.

22. Höflich, K.; Yang, R. B.; Berger, A.; Leuchs, G.; Christiansen, S., The Direct Writing of Plasmonic Gold Nanostructures by Electron-Beam-Induced Deposition. Adv. Mater. 2011, 23 (22-23), 2657-2661.

23. Kneipp, K.; Moskovitz, M.; Kneipp, H., Surface-Enhanced Raman Scattering. 1 ed.; Springer-Verlag Berlin Heidelberg: 2006; p 466.

24. Bozhevolnyi, S. I.; Khurgin, J. B., The case for quantum plasmonics. Nat. Photonics 2017, 11 (7), 398-400.

25. Szymańska, I. B., Influence of the gas phase composition on the properties of bimetallic $\mathrm{Ag} / \mathrm{Cu}$ nanomaterials obtained via chemical vapor deposition. Polyhedron 2013, 65, 82-88.

26. Szymańska, I. B., Gaseous phase studies of new copper(II) carboxylate complexes with tert-butylamine as potential precursors for chemical vapor deposition (CVD). Polyhedron 2013, 50 (1), 200-207.

27. Piszczek, P.; Szymańska, I. B.; Talik, E.; Heimann, J., Deposition of Thin Copper Layers using Copper(II) Carboxylate Complexes with tert-Butylamine as New CVD Precursors. Chem. Vap. Depos. 2013, 19 (7-8-9), 251-259.

28. Szymańska, I. B.; Piszczek, P.; Szłyk, E., Gas phase studies of new copper(I) carboxylates compounds with vinylsilanes and their application in Chemical Vapor Deposition (CVD). Polyhedron 2009, 28 (4), 721-728.

29. Szłyk, E.; Piszczek, P.; Grodzicki, A.; Chaberski, M.; Goliński, A.; Szatkowski, J.; Błaszczyk, T., CVD of AgI Complexes with Tertiary Phosphines and Perfluorinated Carboxylates - A New Class of Silver Precursors. Chem. Vap. Depos. 2001, 7 (3), 111-116.

30. Höflich, K.; Jurczyk, J.; Zhang, Y.; Puydinger dos Santos, M. V.; Götz, M.; Guerra-Nuñez, C.; Best, J. P.; Kapusta, C.; Utke, I., Direct Electron Beam Writing of Silver-Based Nanostructures. ACS Appl. Mater. Interfaces 2017, 9 (28), 24071-24077.

31. Berger, L.; Madajska, K.; Szymanska, I. B.; Höflich, K.; Polyakov, M. N.; Jurczyk, J.; GuerraNuñez, C.; Utke, I., Gas-assisted silver deposition with a focused electron beam. Beilstein J. Nanotech. 2018, 9, 224-232.

32. Blakeslee, A. E.; Hoard, J. L., The Structure of Silver Perfluorobutyrate1. J. Am. Chem. Soc. 1956, 78 (13), 3029-3033.

33. Kuzmina, N.; Paramonov, S.; Ivanov, R.; Kezko, V.; Polamo, K.; Troyanov, S., Silver pivalate as a new volatile precursor for thin film deposition. J. Phys. IV France 1999, 09 (PR8), Pr8-923-Pr8-928.

34. Szymańska, I.; Piszczek, P.; Szczęsny, R.; Szłyk, E., Thermal and MS studies of silver(I) 2,2dimethylbutyrate complexes with tertiary phosphines and their application for CVD of silver films. Polyhedron 2007, 26 (12), 2440-2448.

35. Jurczyk, J.; Glessi, C.; madajska, K.; Berger, L.; Nyrud, J. I. K.; Szymanska, I.; Kapusta, C.; Tilset, M.; Utke, I., Vacuum vs Ambient Pressure Inert Gas Thermogravimetry: A Study of Silver Carboxylates. J. Therm. Anal. Calorim. 2020, (accepted).

36. Friedli, V.; Utke, I. GIS Simulator, 5; EMPA: https://www.empa.ch/web/s206/febip-codes, 2015.

37. Friedli, V.; Utke, I., Optimized molecule supply from nozzle-based gas injection systems for focused electron- and ion-beam induced deposition and etching: simulation and experiment. J. Phys. D: Appl. Phys. 2009, 42 (12), 125305.

38. StrataGEM, samX: rue Galilée, 78280 Guyancourt, France. 
39. Hodoroaba, V.-D.; Kim, K. J.; Unger, W. E. S., Energy dispersive electron probe microanalysis (EDEPMA) of elemental composition and thickness of Fe-Ni alloy films. Surf. Interface Anal. 2012, 44 (1112), 1459-1461.

40. Höflich, K.; Jurczyk, J. M.; Madajska, K.; Götz, M.; Berger, L.; Guerra-Nuñez, C.; Haverkamp, C.; Szymanska, I.; Utke, I., Towards the third dimension in direct electron beam writing of silver. Beilstein J. Nanotech. 2018, 9, 842-849.

41. Porrati, F.; Sachser, R.; Huth, M., The transient electrical conductivity of W-based electron-beaminduced deposits during growth, irradiation and exposure to air. Nanotechnology 2009, 20 (19), 195301.

42. Utke, I.; Hoffmann, P.; Dwir, B.; Leifer, K.; Kapon, E.; Doppelt, P., Focused electron beam induced deposition of gold. J. Vac. Sci. Technol. B 2000, 18 (6), 3168-3171.

43. Toth, M.; Lobo, C.; Friedli, V.; Szkudlarek, A.; Utke, I., Continuum models of focused electron beam induced processing. Beilstein J. Nanotech. 2015, 6, 1518-1540.

44. Gommes, C. J., Ostwald ripening of confined nanoparticles: chemomechanical coupling in nanopores. Nanoscale 2019, 11 (15), 7386-7393.

45. Sanz-Hernández, D.; Fernández-Pacheco, A., Modelling focused electron beam induced deposition beyond Langmuir adsorption. Beilstein J. Nanotech. 2017, 8, 2151-2161.

46. Demers, H.; Poirier-Demers, N.; Couture, A. R.; Joly, D.; Guilmain, M.; de Jonge, N.; Drouin, D., Three-dimensional electron microscopy simulation with the CASINO Monte Carlo software. Scanning 2011, 33 (3), 135-146. 